\title{
Próximo número
}

Tema

"La integración de la Docencia y la Extensión.

Un desafío para el currículo universitario"

Diseñar prácticas de extensión integradas al currículo universitario supone brindar la oportunidad a los estudiantes universitarios de involucrarse en la resolución de problemas reales de la comunidad, trabajando en escenarios complejos, en los que se debe poner a prueba el conocimiento académico, la interdisciplina y la pluralidad de profesiones en interacción con otros actores sociales. Para el currículo universitario, implica problematizar y resignificar las prácticas de enseñanza y posibilitar otras formas de aprender y de evaluar procesos que apuesten a una formación más integral de los futuros profesionales.

La definición de este tipo de experiencia supone integrar contextos y contenidos curriculares; articular lógicas institucionales diversas; fomentar habilidades sociales en los estudiantes; incentivar el trabajo en equipo; reconocer y respetar las trayectorias y saberes de actores sociales involucrados en las prácticas; tener una mirada crítica sobre problemáticas sociales; por señalar sólo algunas cuestiones.

Así, los modos de integrar la docencia con la extensión se apoyan en diversos enfoques teóricos, epistemológicos y metodológicos que definen políticas institucionales y dan lugar una variedad de prácticas e intervenciones.

Es esta diversidad la que se pretende explorar, poner en juego y debatir en este número 6 de la revista de extensión $+\mathrm{E}$.
Se podrán presentar artículos en cuatro secciones:

- Perspectivas: es un espacio en el que se apuesta a brindar panoramas respecto de las discusiones teóricas, conceptuales y metodológicas con relación al campo del conocimiento, de la enseñanza, de los aprendizajes integrados a las prácticas de extensión, en donde se ponen en juego los marcos disciplinares y la formación del futuro profesional.

- Desafíos de gestión: incluye artículos que den cuenta de las estrategias de la gestión universitaria que expongan los desafíos, limitaciones y potencialidades para la implementación de las políticas universitarias de incorporación curricular de la extensión.

- Intervenciones: comprende trabajos que deriven de proyectos o programas universitarios que hayan implementado este tipo de experiencias concretas en los que se reflexione o se visibilicen aspectos críticos o potenciales (teóricos, metodológicos, políticos o prácticos) tanto para los equipos como para los beneficiarios de dichas prácticas. Se puede incluir en este apartado a miembros de organizaciones vinculados a prácticas de extensión universitaria, como coautores de los artículos.

- Reseñas de libros: este apartado abarca reseñas de libros vinculados a la temática de la convocatoria. Las mismas deben tener como objetivo la presentación de libros de actualidad y señalar el aporte teórico-metodológico para este tipo de prácticas de extensión.

\section{Proceso de evaluación de los artículos}

Los artículos serán sometidos a la consideración del Consejo Editorial (evaluación de pertinencia) y al Comité de Referato conformado especialmente para la temática (evaluación de calidad), bajo el sistema de "doble ciego". Las consideraciones de los evaluadores son inapelables.

A partir de la evaluación de pertinencia y de calidad, el Consejo Editorial seleccionará aquellos trabajos que integrarán la edición impresa y los trabajos que serán editados en la versión digital. +E no se hace responsable por los trabajos no publicados.

\section{Pautas para la publicación}

Los artículos podrán presentarse en idioma español o portugués; deberán ser inéditos y observar las siguientes recomendaciones:

\section{1) Modalidad de presentación:} serán enviados en archivo digital, con un formato en Microsoft Office Word 97-2003.

2) Autores: hasta 4 autores. Los datos del/os autor/es (nombre y apellido; pertenencia académica y cargo; mail institucional) deberán constar en el cuerpo del mail en el que se adjunta el trabajo y no en el artículo (que será anónimo para su evaluación).

3) Formato: $A 4$, márgenes de $2 \mathrm{~cm}$, Times New Roman 12, interlineado simple, justificado a la izquierda sin sangría, ni guiones.

\author{
- Para la sección Perspectivas: \\ los artículos no podrán exceder \\ las 10 páginas. \\ - Para las secciones de Desafíos \\ de gestión e Intervenciones: no \\ podrán exceder las 7 páginas. \\ - Para Reseñas de libros: sólo \\ será de una 1 carilla. \\ 4) Notas: deben incluirse con la \\ opción "Insertar notas al pie" Se \\ recomienda que las mismas sean \\ breves. La tipografía deberá ser \\ Times New Roman 10. \\ 5) Citas: las citas incluidas en el \\ párrafo irán entre comillas y con \\ letra normal; deben incluir los da- \\ tos para identificar el texto citado \\ y el número de página corres- \\ pondiente. Por ejemplo: (Derrida, \\ 1972:32). \\ 6) Bibliografía: sólo se referenciará \\ la que está citada en el cuerpo del \\ texto. Se incluirá al final del artícu- \\ lo, ordenada alfabéticamente por \\ autor, siguiendo las normas APA. \\ Las bases, condiciones y el \\ proceso de evaluación se podrá \\ descargar en www.unl.edu.ar/ \\ extensión/publicaciones/revista+E
}

\section{Plazo de entrega} de los artículos: viernes 24 de junio de 2016

Envío del artículo a: revistaextension@unl.edu.ar 